\title{
Promotion Path of Transmission Efficiency of Jingchu Cultural Symbols under the New Media Environment
}

\author{
Yongxia Zhang \\ Wuhan University of Technology, Wuhan, China
}

Keywords: Cultural symbols, Jingchu culture, Transmission efficiency, New media

\begin{abstract}
The new media, represented by the internet and the mobile Internet, has been showing strong growth in recent years. It has a wide range of influence and has caused great changes in all aspects of social life. In the new media environment, the vigorous development of the cultural and communication industry is also being reshaped. Jingchu culture is an important part of Chinese culture and has unique communication value. With the help of new media platforms such as microblog and WeChat subscription, and the transmission format of image and video, Jingchu culture symbols can be widely disseminated. Based on DEA, this paper selects economic input, human resources input and innovation input as the input variables, selects the economic output, achievements output and innovation output as the output variables to calculate the transmission efficiency of Jingchu cultural symbols under the new media environment. The path to enhance the efficiency of Jingchu culture symbols includes the innovation of communication contents and the improvement of communication technology.
\end{abstract}

\section{Introduction}

With the rapid development of internet technology and the improvement of the living standard, almost every family is connected to the internet, and the use rate of mobile media, such as mobile phone and tablet computer is also increasing. With the rapid development of social networks such as micro-blog and WeChat, the dissemination and inheritance of Jingchu culture presents new characteristics and trends. The diversity of new media makes Jingchu culture spread in many ways. Most people accept information through mobile phones. People can see all kinds of news in different places by setting up WeChat group and looking at WeChat's circle of friends. By subscribing to WeChat subscriptions, people can understand video, text, audio of different fields of interest to individuals. People browse information at anytime and anywhere through small and touchable screens. Nowadays, the function of new media and its powerful functions have surpassed some functions of traditional media, and at the same time, they have the function that traditional media do not possess. It is easy to accept this way of communication for new media. It is more and more satisfied with people's needs and becomes an indispensable part of the life of more and more people. At the same time, with the widespread use of new media, the content of the new media, compared with the traditional media, can impress the audience and stimulate the audiences' participation.

Before the emergence of new media, Jingchu culture has a relatively simple environment. The audience understands the Jingchu culture symbols, but after all, the channels of communication are single and the communicators are few. After the new media spread the variety of the Jingchu culture, the Jingchu cultural symbol began to enter the cognition of the external audience with the color of personal interpretation, the audience from strange to understanding, to the curiosity, and then to actively participate in interaction and communication. Then new cognition is formed. These new cognitions not only promote cultural exchange, but also help to spread culture widely. The communication environment will receive different interpretations and different voices because of its cognition and interpretation. Effective response to these sounds can help to raise the relevance of cultural communication. The use of new media to communicate is now a favourite way for young people and even the elderly. Sometimes the young people of the two countries have an intersection and discussion of a political problem, and the scope of their discussion will expand instantaneously 
and reach the maximum extent, causing extensive discussion on social media. Participation in a wide range of discussions is an essential pleasure in their lives. The new media is now the most important mode of communication, and anyone should use the new media at any time. The simplicity of the new media has brought convenience to people's life. Participation in discussion is equal for everyone and will not prevent you from taking part in the discussion for your individual reasons. Your remarks will be taken seriously, and your casual publication will even bring you different results. Therefore, the new media has brought us different communication experiences.

\section{Transmission of Jingchu cultural symbols}

\subsection{Jingchu cultural symbols}

Jingchu cultural symbols are carried by bronze, lacquerware, pottery, jade, glaze, gold and silver. The folk toys, instruments, masks, articles of life and sacrificial articles are engraved with the traces of the unique cultural symbols of Jingchu. These cultural symbols reflect the romantic feelings and spirit of life in Jingchu culture. Its origin is from the special river, the creation of Jingchu people, the creator of Jingchu culture, and the unique period and mature stage of the formation of Jingchu culture. Jingchu culture has a profound influence on Romanticism in Chinese traditional culture. With more and more cultural relics unearthed, the characteristics of the utensils in Jingchu area are becoming more and more clear, and the research on the objects of the carrier of Jingchu culture is becoming more and more deep. There are various kinds of cultural symbols in Jingchu. They are the results of the combination of the lines, the outline, the structure and the color of the ancient energy craftsmen to extract material from the natural and social life, to process, conceive and deduce, make it typical, patterned, regularized and abstract. As the carrier of Jingchu cultural symbols, bronze ware, lacquerware, pottery, jade, glaze, gold and silver, as well as folk toys, instruments, masks of gods, articles of life, and sacrificial articles are engraved with the traces of the unique cultural symbols of Jingchu. In the Jingchu culture symbol system, there are some magical scenes that show ghosts, gods, heaven and earth. These scenes are unique semantic expressions in Jingchu culture. This is a manifestation of the universal view of nature and the theory of holiness in Jingchu people. In the ideographic system of Jingchu culture, nature is regarded as the existence of the power of life. In these paintings, the world of celestial gods, the world of the world and the world of ghosts and gods are integrated into one. It is an expression of the natural view of the Jingchu people with the spirit of spirit. In the system of Jingchu cultural symbols, most of them show the spiritual essence of Jingchu culture with the help of the flying dragon and floating Phoenix. Therefore, in the semantic system of Jingchu culture, it has the spirit of spirit and elegance. This elegance is beyond the fetters of real life, and it is a manifestation of the beauty of boundless oceans.

\subsection{Transmission value of Jingchu cultural symbols}

Mental strength is an integral part of the national comprehensive strength, which embodies the soul of the nation. The semantic spread of these cultures has a profound impact on the development of regional society and economy. In the Eleventh Century BC, the Chu people moved to Jingchu area, which was remote and economically backward, and suffered discrimination and aggression for a long time. Such geographical position and historical status stimulated the strong spirit of the Chu people to strengthen their national spirit. They continued to open and become stronger from weak to strong. It was also the great enterprising spirit that promoted it to grow from the small tribes of the weekend to a great country which occupies an important position in the great power as the forest. Chu people dare to break the rules and actively explore new measures for national governance. The county system continues to this day. In addition, Chu people have made remarkable achievements in science and technology, philosophy and literary creation. Compared with the other ethnic groups in the pre-Qin period, Chu people have the weakest national prejudice, pay great attention to the national unity and strive to achieve the culture of other nationalities. The limited and poor resources must actively study the length of others, make up his own short, and finally achieve the quality of the Chu people's inclusiveness, diversity and pragmatism. Drawing on the bronze smelting 
technology in Wu Yue area, this kind of fine quality of Chu people is strongly proved. The characteristics of Jingchu culture and art are prominent, with the main features of witty and strange, brilliant and brilliant. The art of painting and sculpture of Chu state is full of fantasy of the unknown world, with rich imagination space, mysterious and unconstrained works, not only full of original wild vitality, but also full of romantic passion. The beauty of sports is full of movement, mobility and vitality, and the beauty of colour coexisting with bright and complex. The rich colon design, bold design and quality design of the Chu people are of great enlightening and guiding value to modern cultural and artistic creation.

\subsection{Transmission models of Jingchu cultural symbols}

With the highly integration of traditional culture and new media, the dissemination of Jingchu culture is more inclusive and participatory. We should increase the development and utilization of new media technology, and form a complete value chain with the creativity, design, production, distribution and consumption of Jingchu culture. The large screen surround with high technology lighting, sound and dance is a comprehensive performance of drama, film and audience interaction experience. While achieving economic benefits, we also gained good social reputation. Jingchu culture industry will achieve good results only if it propagates with high technology and new media based on excellent creative planning. Conduct public opinion guidance. To explore the potential factors of the development of the Jingchu culture with the "relationship thinking", use the new media to carry out the dissemination rationally, guide the selection of the audience's cultural diversity by means of encouragement, design and create the derivatives of the Jingchu culture, and broaden the breadth and practicality of the culture of the Jingchu culture. And by showing the diversity of Jingchu culture, new media can become a bridge linking Jingchu culture with other cultures. At the same time, using micro-blog and WeChat to publicize and guide, set up public number, create topic, cause discussion and attention, so that the public can understand the Jingchu culture more. The topic has aroused widespread debate among the audience and actively participated in the activities. In the Internet plus under the environment of new media gradually formed the image as the leading postmodern cultural phenomenon, and visual expression way has become the most prominent characteristic of modern culture. Video images with visual impact and infectious force create the cultural diversity, but also make the communication of Jingchu culture fragmented and divided and attract more audience. Through the packaging and display of media technology, Jingchu culture can be re-examined, defined, understood and accepted by people. All kinds of cultural activities have been warmly welcomed and actively participated by young people. These interactive forms of expression are also easier for young people to understand and deepen their cultural perception.

\section{Transmission efficiency calculation of Jingchu cultural symbols under the new media environment}

\subsection{DEA theory}

DEA is a linear programming model, which is expressed as the ratio of output to input. By comparing the efficiency of a specific unit with the performance of a group of similar units offering the same services, it tries to maximize the efficiency of service units. The main advantage of DEA lies in its wide application and low operational difficulty. This method can be applied to the analysis and research of many industries. DEA is applicable to multiple input and output objects, and specific parameters are calculated for the decision units contained in these inputs and outputs. The main difference between this method and other analytical methods is that the complex production relationship can be evaluated without setting corresponding functions. Mainly in the following aspects: variables mainly include two kinds, namely input weight and output weight, and select the most favourable way for decision making unit evaluation. Suppose that all inputs have corresponding output, that is, one to one correspondence or one to many correspondences. In DEA computing, it is not necessary to make clear the specific relationship between decision units, avoid the influence of subjective factors on the result, and make the evaluation result objectivity higher. 
Compared with the parameter method, the method does not need to consider the influence of the production function and does not need to determine the specific form of function. It greatly reduces the calculation work and avoids the problem of evaluation and analysis error due to the wrong function form. The evaluation of DMU has nothing to do with the category of units in input output data. In the process of evaluation, the input and output data units are the same, and the result of efficiency evaluation is not affected by the simultaneous change of input and output data units. Input and output data are the main indicators reflecting the input or output of decision making units, so the proportional and non-proportional data can be processed at the same time. The weight of input and output in the DEA model does not need to be set in advance. The mathematical programming is produced according to the data, and it will not affect the result according to the different subjective ideas. DEA can carry out comparative analysis, sensitivity analysis and efficiency analysis of target value and actual value.

\subsection{DMU and index selection}

The dissemination of Jingchu culture symbol is a complex system with multiple inputs and multiple outputs. The selection of input and output indicators for efficiency analysis of Jingchu culture should follow the principle of representativeness and availability. The evaluation index of cultural symbol transmission efficiency is to measure the feasibility of cultural symbol communication project through the ratio of input and output. Each index should be quantified to the greatest extent, and qualitative analysis cannot be used to quantify the important indicators, to make up for the shortage of simple quantitative evaluation. The index should be directly influenced by the evaluation results, so the evaluation index should be accurate, horizontal and vertical, and the influence of technical parameters and other uncertain factors should be considered. As the communication of cultural symbols is composed of many different projects, it has the complexity of more input and more production. The selected evaluation body should be able to input and output multiple indicators at the same time, to evaluate the overall cultural symbol transmission efficiency of the company. The more indicators, the better. The more indicators, the greater the difficulty and cost of collecting data. Therefore, in the design of the index system, we should consider the comprehensiveness and simplification of the indicators, try to delete repeated indicators, use as few indicators as possible and cover as low as possible as possible to cover the full information. To comprehensively and accurately transmit the efficiency of Jingchu culture symbols, we must analyse the ratio of input output. Therefore, when selecting indicators, we should adhere to the principle of combining social benefits with economic benefits. We select ten relative micro-blogs and ten WeChat subscriptions as the DMU, selects economic input, human resources input and innovation input as the input variables, selects the economic output, achievements output and innovation output as the output variables to calculate the transmission efficiency of Jingchu cultural symbols under the new media environment.

Table 1. Input and output indexes of each new media platforms

\begin{tabular}{|c|c|c|c|c|c|c|}
\hline Index name & $\begin{array}{c}\text { Economic input } \\
\mathrm{X}_{1}\end{array}$ & $\begin{array}{l}\text { Human } \\
\text { resources } \\
\text { input } \mathrm{X}_{2} \\
\end{array}$ & $\begin{array}{l}\text { Innovation } \\
\text { input } \mathrm{X}_{3}\end{array}$ & $\begin{array}{l}\text { Economic } \\
\text { output } \mathrm{Y}_{1}\end{array}$ & $\begin{array}{l}\text { Achievements } \\
\text { output } \mathrm{Y}_{2}\end{array}$ & $\begin{array}{c}\text { Innovation } \\
\text { output } \mathrm{Y}_{3}\end{array}$ \\
\hline WeChat Subscription 1 & 185.3 & 10 & 58 & 941.8 & 1078.0 & 47 \\
\hline WeChat Subscription 2 & 197.2 & 9 & 87 & 523.2 & 1514.9 & 36 \\
\hline WeChat Subscription 3 & 128.1 & 10 & 34 & 692.2 & 938.2 & 79 \\
\hline WeChat Subscription 4 & 128.5 & 8 & 87 & 992.9 & 930.7 & 14 \\
\hline WeChat Subscription 5 & 105.3 & 10 & 90 & 465.1 & 573.6 & 75 \\
\hline WeChat Subscription 6 & 90.3 & 8 & 88 & 575.8 & 1805.1 & 55 \\
\hline WeChat Subscription 7 & 93.7 & 5 & 48 & 356.2 & 1304.2 & 74 \\
\hline WeChat Subscription 8 & 67.4 & 4 & 24 & 973.3 & 936.8 & 24 \\
\hline WeChat Subscription 9 & 34.8 & 3 & 61 & 453.5 & 1591.6 & 78 \\
\hline WeChat Subscription 10 & 185.5 & 7 & 15 & 859.3 & 656.1 & 18 \\
\hline Micro-blog 1 & 200.5 & 2 & 60 & 451.7 & 1968.1 & 79 \\
\hline Micro-blog 2 & 45.6 & 2 & 81 & 556.7 & 1994.2 & 69 \\
\hline Micro-blog 3 & 132.0 & 4 & 51 & 856.1 & 1419.2 & 61 \\
\hline Micro-blog 4 & 63.3 & 7 & 59 & 716.9 & 1248.1 & 97 \\
\hline Micro-blog 5 & 157.5 & 3 & 49 & 342.6 & 920.0 & 37 \\
\hline
\end{tabular}




\begin{tabular}{|c|c|c|c|c|c|c|}
\hline Micro-blog 6 & 32.3 & 10 & 84 & 815.7 & 770.0 & 20 \\
\hline Micro-blog 7 & 118.0 & 10 & 65 & 714.4 & 852.6 & 53 \\
\hline Micro-blog 8 & 35.8 & 4 & 80 & 903.1 & 1197.1 & 13 \\
\hline Micro-blog 9 & 117.2 & 5 & 14 & 985.2 & 1227.4 & 70 \\
\hline Micro-blog 10 & 82.3 & 7 & 94 & 565.0 & 1259.8 & 68 \\
\hline
\end{tabular}

\subsection{Operational result}

This paper calculates the comprehensive transmission efficiency, pure technology transmission efficiency and scale transmission efficiency of each new media platform, analysis software adopts DEAP2.1, and BCC model is selected. The results are shown in Table 2.

Table 2. Operational result of transmission efficiency of Jingchu cultural symbols

\begin{tabular}{|c|c|c|c|c|}
\hline Village Order & $\begin{array}{c}\text { Comprehensive } \\
\text { Efficiency }\end{array}$ & $\begin{array}{c}\text { Pure Technology } \\
\text { Efficiency }\end{array}$ & Scale Efficiency & Scale Return \\
\hline WeChat Subscription 1 & 0.896 & 0.995 & 0.901 & irs \\
\hline WeChat Subscription 2 & 0.996 & 1.000 & 0.996 & irs \\
\hline WeChat Subscription 3 & 0.852 & 0.818 & 0.993 & drs \\
\hline WeChat Subscription 4 & 0.787 & 0.796 & 0.989 & drs \\
\hline WeChat Subscription 5 & 0.982 & 1.000 & 0.982 & irs \\
\hline WeChat Subscription 6 & 0.932 & 0.954 & 0.978 & irs \\
\hline WeChat Subscription 7 & 0.749 & 0.767 & 0.976 & irs \\
\hline WeChat Subscription 8 & 0.810 & 0.835 & 0.970 & irs \\
\hline WeChat Subscription 9 & 0.772 & 0.819 & 0.943 & drs \\
\hline WeChat Subscription 10 & 0.826 & 0.887 & 0.920 & irs \\
\hline Micro-blog 1 & 0.698 & 0.769 & 0.908 & irs \\
\hline Micro-blog 2 & 0.733 & 0.812 & 0.903 & drs \\
\hline Micro-blog 3 & 0.862 & 0.992 & 0.869 & irs \\
\hline Micro-blog 4 & 0.678 & 0.784 & 0.865 & irs \\
\hline Micro-blog 5 & 0.739 & 0.859 & 0.860 & irs \\
\hline Micro-blog 6 & 0.808 & 0.949 & 0.852 & irs \\
\hline Micro-blog 7 & 0.708 & 0.744 & 0.951 & drs \\
\hline Micro-blog 8 & 0.656 & 0.774 & 0.848 & irs \\
\hline Micro-blog 9 & 0.817 & 0.972 & 0.841 & irs \\
\hline Micro-blog 10 & 0.504 & 0.645 & 0.781 & irs \\
\hline
\end{tabular}

\section{Promotion Path of Transmission Efficiency of Jingchu Cultural Symbols}

We should make use of the interactive nature of new media to bring Jingchu culture into a new media environment. Since twenty-first Century, relying on the update of communication technology, we have entered the "explosive" communication environment. New media is different from the single line transmission mode of traditional media. The new media, represented by micro-blog and WeChat, rely on the spontaneous content manufacturing behavior of users, and interaction becomes an important link in the process of communication. The age of the user group is light, which belongs to the generation of the visual culture. It is used to the fast rhythm information transmission mode and pays more attention to the interaction factors in the process of communication. In the process of dissemination, Jingchu culture should make full use of the interactive characteristics of new media, to adapt Jingchu culture to modern communication environment. To enhance interaction with users and enhance their exposure rate is the first step to open the network of Jingchu culture. In addition, the operation of the Jingchu culture website is also very important. At present, most of the popular science-based websites in China are comprehensive, and do not make full use of the technical advantages of the Internet platform multimedia. In the process of design, Jingchu culture network should be distinguished from the traditional mode of communication, to get rid of the serious and rigid stereotype of people's own cultural knowledge, and to use Flash and other multimedia means to increase the interest and interaction of communication, and to simplify 
the decoding process of the audience's culture.

The big data produced in the new media environment can make us look at the essence from the complex phenomenon, which is beneficial to the development of all walks of life and the analysis of different cultural phenomena. The influence of big data has changed from technology mode to thinking mode, and our values have been changed based on information dissemination. The development of traditional culture requires the support of large data, processing, capturing and managing all kinds of valuable data, using new models to make decisions and insight into the direction of cultural development, to adapt to the high growth of the massive and diversified traditional cultural information assets. The timely processing of useful information, the thorough excavation of massive data and the deep processing of traditional culture related data can achieve the value added of cultural industry. Jingchu culture can be further expanded and extended through new media, for social interaction and cultural interaction. Let traditional culture inherit among all kinds of audiences, so that young people can actively contact excellent traditional culture. Smart phone centric mobile computer equipment will gradually move towards unified integration. Among them, smart phones will gradually become the backbone of driving tablet, desktop operating system, high-definition TV, game equipment and various intelligent terminals. Therefore, as the most representative medium of new media, mobile phones will become an important carrier for spreading culture and carrying culture. The dissemination of traditional culture cannot be separated from the important new media of mobile phones. The appearance of WeChat, micro-blog and various kinds of APP creates infinite possibilities for the spread of Jingchu culture.

\section{Conclusions}

The rapid development of new media provides fertile soil for the dissemination and exchange of Jingchu cultural symbols. This paper discusses some problems of the dissemination of Jingchu culture in the new media environment. The main conclusions are as follows:

(1) This paper analyses the transmission value and models of Jingchu cultural symbols under the new media environment.

(2) This paper selects the economic input, human resources input and innovation input as the input variables, selects the economic output, achievements output and innovation output as the output variables to calculate the transmission efficiency of Jingchu cultural symbols under the new media environment based on DEA.

(3) We should innovate the communication contents and improve the communication technology of the Jingchu cultural symbols to promote the transmission efficiency under the new media environment.

\section{References}

[1] Ma X, Luo L, Geng Y, et al. Oxytocin increases liking for a country's people and national flag but not for other cultural symbols or consumer products[J]. Frontiers in behavioral neuroscience, 2014, 8: 266.

[2] Parsons J. "Cheese and Chips out of Styrofoam Containers": An Exploration of Taste and Cultural Symbols of Appropriate Family Foodways[J]. M/C Journal, 2014, 17(1).

[3] Olaussen B. The Trademark Holi Wars and the Case for Protecting Religious and Cultural Symbols and Names from Commercial Exploitation[J]. J. Pat. \& Trademark Off. Soc'y, 2014, 96: 298.

[4] Kreuzbauer R, Keller J. The authenticity of cultural products: A psychological perspective[J]. Current Directions in Psychological Science, 2017, 26(5): 417-421.

[5] Becker J C, Kraus M W, Rheinschmidt-Same M. Cultural expressions of social class and their implications for group-related beliefs and behaviors[J]. Journal of Social Issues, 2017, 73(1): 158174. 
[6] Casas M R. Malinche, Pocahontas, and Sacagawea: Indian Women as Cultural Intermediaries and National Symbols by Rebecca K. Jager[J]. 2017.

[7] Carrillo E, Fiszman S, Lähteenmäki L, et al. Consumers' perception of symbols and health claims as health-related label messages. A cross-cultural study[J]. Food research international, 2014, 62: 653-661.

[8] JIANG T, LI J. RegionalLabels and Cultural Symbols: Re-exploration of Changes of Administrative Region in Cangwu Prefecture and Guangxin County during the Han and Tang Dynasties[J]. Journal of Guangxi Normal University (Philosophy and Social Sciences Edition), 2015, 5: 027.

[9] Vilhena D A, Foster J G, Rosvall M, et al. Finding cultural holes: How structure and culture diverge in networks of scholarly communication[J]. Sociological Science, 2014, 1: 221-239.

[10] Skelcher C, Smith S R. Theorizing hybridity: Institutional logics, complex organizations, and actor identities: The case of nonprofits[J]. Public administration, 2015, 93(2): 433-448.

[11] Veresov N. Marxist and non-Marxist aspects of the cultural-historical psychology of LS Vygotsky[J]. Psychological Science, 2018, 7(1).

[12] Meliono I. Understanding the Nusantara thought and local wisdom as an aspect of the Indonesian education[J]. TAWARIKH, 2016, 2(2).

[13] Yingyan G, Lingyun Y. Creative Design of Modern Ethnic Furniture Based on Decoration Symbols of Liangshan Yi Ethnic Group[J]. Furniture \& Interior Design, 2015, 10: 034.

[14] Chu Y J, Lee J Y, Shin S R, et al. A method for cell culture and maintenance of ammoniaoxidizing archaea in agar stab[J]. Indian journal of microbiology, 2015, 55(4): 460-463.

[15] Liu Y, Yao W, Si L, et al. Chinese herbal extract Su-duxing had potent inhibitory effects on both wild-type and entecavir-resistant hepatitis B virus (HBV) in vitro and effectively suppressed HBV replication in mouse model[J]. Antiviral Research, 2018, 155: 39-47.

[16] Choi Y J C, Kim G J. Over-expression of recombinant proteins with N-terminal His-tag via subcellular uneven distribution[J]. Acta Biochim Biophys Sin, 2015, 47(8): 488-495. 